\title{
The Effects of Verb Tense Variation on the Fluency in Monologues by TOEFL iBT Candidates
}

\author{
Ali Akbar Jafarpour \\ English Department, Shahrekord University, Shahrekord, Iran \\ Mahmood Hashemian \\ English Department, Shahrekord University, Shahrekord, Iran \\ Majid Rafati \\ English Department, Shahrekord University, Shahrekord, Iran
}

\begin{abstract}
The literature on fluency and the contributing factors to it is rich (e.g., Chambers, 1997; Foster \& Skehan, 1996; Freed, 2000; Kormos \& Dénes, 2004; Lennon, 1990; Mehnert, 1998; Towell et al., 1996; Yuan \& Ellis, 2003). Previous studies are conducted on a number of factors affecting fluency such as pretask planning and fluency (e.g., Foster \& Skehan, 1996), task repetition and fluency (e.g., Bygate, 2001), the longitudinal development of fluency (Freed, 2000), or formulaic speech and fluency (Riggenbach, 1991). This study, however, adopts a fresh approach in order to assess fluency in monologues by TOEFL iBT candidates. It investigated the possible effects of changing the verb tense on fluency. To this end, the present study benefitted from 40 TOEFL iBT candidates and set out to observe the effects of speaking in past, present, and future tenses on the fluency of the responses. In so doing, the first question of the speaking section on TOEFL iBT exam was used as the model in terms of planning and response times. Therefore, three questions - one in past, one in present, and one in future-were used. The participants had 15 seconds to plan and 45 seconds to respond to each question. All the responses were recorded, and the analyses of the results indicated that, overall, the future tense responses were more fluent. Considering the growing number of university students, who intend to take the TOEFL iBT exam and pursue their studies, the findings may have some implications in second language acquisition (SLA) in general and in speaking skills in particular because those students are normally required to have a decent language proficiency score.
\end{abstract}

Index Terms - fluency, monologue, speaking, TOEFL iBT

\section{INTRODUCTION}

Speaking fluently is surely one of the dreams of any L2 learner. However, the problem is that L2 learners normally find it very difficult to fluently speak the language they learn. This is especially a tough challenge for L2 learners in EFL contexts, where L2 exposure is not sufficient for the learners. DeKeyser (2007) found that a "majority of studyabroad students make measurable progress in speaking, especially in terms of fluency, at least in the programs of longer duration" (p. 211).

Historically, fluency typically refers to a person's general L2 proficiency, particularly as characterized by perceptions of ease, eloquence, and smoothness of speech or writing (Chambers, 1997; Freed, 2000; Guillot, 1999; Hilton, 2008; Koponen \& Riggenbach, 2000; Lennon, 1990). Skehan $(1992,1996)$ defines the concept of fluency as follows. Fluency is the capacity to use an L2 in real time, to emphasize meanings, possibly drawing on more lexicalized systems. In addition, it has been defined as the ability to process an L2 with "native-like rapidity" (Lennon, 1990 p. 390) or "the extent to which the language produced in performing a task manifests pausing, hesitation, or reformulation" (Ellis, 2003 p. 342). Hence, from the literature on fluency, it is inferred that it is generally associated with the smoothness and continuity of the talk.

In order to find out which L2 elements contribute to L2 fluency, SLA researchers (e.g., Cucchiarini et al., 2002; Kormos \& Dénes, 2004; Lennon, 1990; Towell et al., 1996) have mainly concentrated on participants' oral production and tried to recognize factors helping participants to make their L2 production more fluent. Findings suggest that fluency is a multi-dimensional element that can be categorized into some branches, such as speed fluency (i.e., rate and density of delivery), breakdown fluency (i.e., number, length, and distribution of pauses in speech), and repair fluency (i.e., number of false starts and repetitions; Tavakoli \& Skehan, 2005). Moreover, previous studies indicate that both pretask planning (Foster \& Skehan, 1996; Mehnert, 1998; Yuan \& Ellis, 2003) and task repetition (Bygate, 2000) aid fluency by freeing up attentional resources. 
Research on fluency and factors that contribute to it is extensive (e.g., Foster \& Skehan, 1996; Lennon, 1990; Riggenbach, 1991, 2000; Skehan \& Foster, 1999; Towell et al., 1996; Wood, 2001). However, much of the research into fluency progress, made by L2 learners, has been carried out by comparing computational differences in Interlanguage samples with assessing those samples made by native speakers in order to find what fluency measures play the most important role in fluency development. Lennon (1990) took this approach and found that change in dysfluency markers, including repetitions and self-corrections, could not explain native speakers' ratings of L2 learner fluency. Derwing et al. (2004), using a similar methodology, also found that self-repetitions did not correlate much with native speaker ratings of fluency. In spite of this fact, they could find that, especially among lower-level L2 learners, temporal measures, such as speech rate correlated well with them. Besides, other research (e.g., Riggenbach, 1991) has looked at how L2 learners of different levels differ from one another with respect to fluency measures. Riggenbach (1991) found that measures of self-repair do not play a major role in distinguishing one level of L2 learner from another. Like Derwing et al. (2004), she also found that rate of speech can be a useful factor in distinguishing one level of learner from another.

Fillmore (1979) is one of the first instances of working on fluency. In his extensive definition of fluency, he categorized the phenomenon in four different ways: First, fluency is defined as the ability to talk at length with few pauses and to be able to fill the time with talk. Second, fluent speakers are not only capable of talking without hesitations but of expressing their message coherently and dense with regard to semantics. Third, a person is considered fluent if he or she knows what to say in a wide range of contexts. Finally, fluent speakers are known to be creative and imaginative in their language use and a maximally fluent speaker has all of the abovementioned abilities.

Kormos (1999) and Dewaele (2002) have argued that there are long-term settings for fluency that depend on individual's speaking style. In spite of such settings, however, studies on task type indicate that there are variations in fluency that can be directly attributed to the properties of a given task. Foster and Skehan (1996) examined three typical tasks: a personal information exchange, a picture narrative, and a collaborative decision-making task. Their study showed that measurements of fluency-related variables on these tasks were different, depending not only on the nature of the task itself but on the availability of planning time. Ejzenberg (2000) argued that L2 learners are perceived as being more fluent in an interaction with a native speaker than in other situations because they have the advantage of using the productions of the interlocutor, too. She suggests that in monologic tasks, the cognitive demands on the speaker are greater, hence negative effects on fluency.

As for the criteria used in measuring the fluency of the oral productions in this study, two general categories were employed: temporal and hesitation. Temporal fluency was checked using two measures: mean length of runs (MLR) and speech rate. MLR was the average number of syllables produced in utterances between pauses of 0.4 seconds and above. Inoue (2010) used the same measure, but the length of pauses was 0.25 seconds and more. Cucchiarini et al. (2002), however, set 0.2 seconds as the pause length. Such values seemed too demanding for the EFL learners of this study; therefore, 0.4 seconds were chosen as a more lenient option. MLR is a contributing factor to fluency, and some studies (e.g., Freed, 1995; Lennon, 1990; Möhle, 1984) have investigated the contribution of longer runs between pauses to fluency. The second measure of temporal fluency was speech rate, which is normally used in studies on fluency (e.g., Freed, 1995; Riggenbach, 1991; Towell, Hawkins \& Bazergui, 1996). Following Ortega (1999), speech rate was calculated by dividing the total number of syllables produced in a given speech sample by the amount of total time required to produce the speech sample (including pause time) expressed in seconds.

Nevertheless, one element missing in the previous studies is whether speaking about, for instance, a past event might be different from that about a present or future event in terms of the fluency of the talk. In fact, the idea behind this study was to observe which of these tenses affects L2 learners' fluency more. Therefore, the following research questions were formed to investigate the possible effects of manipulating verb tenses on fluency of the monologues:

- $\mathrm{H}_{01}$ : There is no relationship between changing the verb tense and the temporal aspects of fluency in a monologue?

- $\mathrm{H}_{02}$ : There is no relationship between changing the verb tense and the hesitation aspects of fluency in a monologue?

- $\mathrm{H}_{03}$ : There is no relationship between changing the verb tense in a monologue and making the talk more fluent in general?

\section{METHODOLOGY}

\section{A. Participants}

A total of 40 advanced L2 learners, 20 male and 20 female, studying English at one of the language institutes in Isfahan, Iran, participated in this study. They ranged in age between 22 and 35. After administering a paper-based TOEFL exam, these participants were chosen from among $70 \mathrm{~L} 2$ learners of the institute; in fact, these 40 participants were the ones who scored above 500 on the TOEFL test. The participants were preparing in a TOEFL iBT course of the institute and were ready to take the exam and leave the country soon. All the participants were living in the very same city, Isfahan, Iran; consequently, the participants' geographical backgrounds were the same.

\section{B. Materials}


In order to collect the data, a language laboratory equipped with computers was used. Each L2 participant sat at a computer and recorded his or her response to the questions of the study. To record the participants' responses, the software adobe audition, version 3, was installed on the computers, too.

\section{Procedure}

This study was an attempt to analyze the fluency of monologues in response to three questions, which appear in Appendix. One of the questions asked for a past experience, the other for a present tense response, and the last for a future plan. The three questions were prepared in advance to elicit responses in these tenses. Prior to launching the study, the participants sat at their computers, wore their headphones, and were ready to record their answers to the questions. The procedure for planning, responding, and recording the responses was exactly similar to that of the TOEFL iBT exam; therefore, first a question appeared on the monitors, then the participants had 15 seconds of planning time and 45 seconds to respond the question. The three questions were answered following the same procedure.

It should only be mentioned that because the participants outnumbered the computers of the laboratory, data collection was carried out in several times, but it all happened in one week time.

\section{Data Analysis}

The present study was an attempt to analyze the fluency of the monologues by 40 TOEFL iBT candidates. To this end, this study employed two measures to check the fluency of the talks, namely temporal and hesitation phenomena. As Table 1 indicates, the temporal aspect of fluency was examined using MLR and speech rate. As explained earlier, MLR was the average syllables produced between pauses of 0.4 seconds and above, and the bigger the value for MLR, the more contribution to temporal fluency of any given talk. The same also applied to speech rate, which was the number of syllables in a talk divided by the total time spent on producing the speech sample (including pause time) expressed in seconds. In fact, bigger values of speech rate indicated better temporal fluency. Table 2 shows that better temporal fluency, both for MLR and speech rate, was obtained in case of future responses. In addition, fluency was checked under another category of fluency features named hesitation. It comprised three features: false starts, the number of repetitions, and the number of reformulations. Freed (2000) associated the same measures with hesitation, or repair in fluency. False starts were the number of utterances abandoned before completion; in fact, the participants sometimes decided to abandon an utterance unfinished, which was counted as a false start. Table 2 indicates that future responses on average had fewer false starts, which is a contributing factor to the hesitation aspect of fluency. The second hesitation criterion was the number of repetitions, calculated by the number of immediate repetitions of a word or a phrase. This value proved the smallest in future tense responses, which showed better results of the hesitation fluency in case of future responses. Finally, the number of reformulations was the third measuring element of hesitation fluency and was measured by the number of phrases or clauses repeated with some modification to syntax, morphology, or word order. This number was at its smallest value for present tense responses.

\section{RESULTS AND DISCUSSION}

The data gathered were, then, subjected to descriptive analyses. The aim was to find which verb-tense responses were the most fluent ones. Prior to this, though, the definitions of the variables used in this study should be explained. Table 1 shows the fluency measures employed in the present study. Although it should be mentioned that the fluency measures of this study are adapted form Inoue (2010), the present researchers modified the MLR criterion, which is explained in the Introduction section.

Using the definitions in Table 1 for each element of fluency, the researchers started to analyze the data. Comparing the means for MLR indicated that the longest MLRs at 9.29 were observed in the future tense responses. This number was followed by the present tense, and the worst results with the mean of 8.52 were related to the past tense responses. Similarly, the speech rate at 2.46 syllables per second was at its highest in future tense responses. Present tense and then past tense stood thereafter. Consequently, the best and the worst results for MLR and speech rate were obtained in future and past tenses, respectively.

The results for hesitation fluency indicted that two measures aced in future responses and one in present tense responses. The first hesitation measure was the number of false starts, which was lowest in future tense at 0.15 . In past tense, though, the number of false starts was the highest, which is a negative factor in fluency of the talk. As for the number of repetitions, the second hesitation measure, again future tense obtained the best results. The mean number of repetitions observed in the future tense was 0.8 , followed by 0.85 in present, and 0.9 in past tense responses. Therefore, the first two hesitation measures were at their best in future tense and the poorest results were observed in past tense. 
TABLE 1.

FLUENCY MEASURES OF THE PRESENT STUDY

\begin{tabular}{|c|c|c|}
\hline Aspect & Measure & Definition \\
\hline Temporal Fluency & MLR & 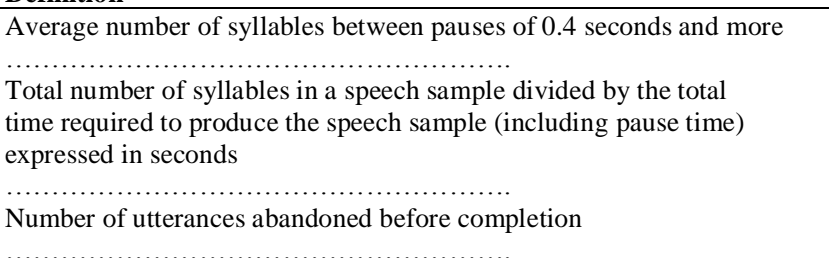 \\
\hline Hesitation Fluency & $\begin{array}{l}\text { False Starts } \\
\text { Repetitions } \\
\text { Reformulations }\end{array}$ & $\begin{array}{l}\text { Number of immediate repetitions of a word or a phrase } \\
\ldots \ldots \ldots \ldots \ldots \ldots \ldots \ldots \ldots \ldots \ldots \ldots \ldots \ldots \ldots \ldots \ldots \\
\text { Number of phrases or clauses repeated with some modification in syntax, } \\
\text { lexicon, or word order }\end{array}$ \\
\hline
\end{tabular}

In case of the last hesitation measure, the results were in favor of the present tense. The number of reformulations was 1.18 in the present tense. In case of the past tense, this value was slightly higher at 1.33 , and the worst number was found in future tense at 1.9. The observed differences here were significant, indicating that in present tense, the participants were less forced to modify their responses as they were replying to the question. Therefore, a one-way ANOVA was run to investigate the probable differences between the samples of the three tenses. Table 2 shows the descriptive statistics observed for the temporal and hesitation measures of fluency in this study:

TABLE 2.

THE DESCRIPTIVE STATISTICS FOR FLUENCY MEASURES

\begin{tabular}{|c|c|c|c|c|c|c|}
\hline Measure & Tense & Min & Max & Mean & $S D$ & $p$ Value \\
\hline \multirow{3}{*}{ MLR } & Present & 3.17 & 14.30 & 8.85 & 3.5 & \multirow{3}{*}{0.46} \\
\hline & Past & 4.50 & 14.67 & 8.52 & 2.9 & \\
\hline & Future & 3.95 & 19.90 & 9.29 & 4.7 & \\
\hline \multirow{3}{*}{ Speech Rate } & Present & 1.42 & 3.62 & 2.39 & 0.6 & \multirow{3}{*}{0.25} \\
\hline & Past & 1.76 & 3.48 & 2.32 & 0.4 & \\
\hline & Future & 1.46 & 3.90 & 2.46 & 0.7 & \\
\hline \multirow{3}{*}{ Number of False Starts } & Present & 0 & 2 & 0.20 & 0.5 & \multirow{3}{*}{0.87} \\
\hline & Past & 0 & 2 & 0.23 & 0.5 & \\
\hline & Future & 0 & 1 & 0.15 & 0.4 & \\
\hline \multirow{3}{*}{ Number of Repetitions } & Present & 0 & 4 & 0.85 & 1.0 & \multirow{3}{*}{0.88} \\
\hline & Past & 0 & 4 & 0.95 & 1.1 & \\
\hline & Future & 0 & 3 & 0.80 & 0.9 & \\
\hline \multirow{3}{*}{ Number of Reformulations } & Present & 0 & 3 & 1.18 & 0.9 & \multirow{3}{*}{$0.004 *$} \\
\hline & Past & 0 & 4 & 1.33 & 1.0 & \\
\hline & Future & 0 & 4 & 1.90 & 1.3 & \\
\hline
\end{tabular}

*: The observed difference is significant at the level of $\mathrm{p}<0.05$.

From observing the results of the study in Table 2, it can be inferred that changing the verb tense in monologues partly contributes to the fluency of the talk. The first four fluency measures used in this study present better results for future tense responses although the difference is not statistically significant. Consequently, manipulating the verb tense of the monologue could exercise some changes in temporal fluency of the talks; both MLR and speech rate were better in future tense responses. Similarly, in the case of hesitation aspects of fluency, the first two measurements, that is, number of false starts and number of repetitions, obtained better results in future tense; the last hesitation measure, however, proved better in case of the present responses. Therefore, statistically speaking, it cannot be argued that verb tense can play a role in contributing to the fluency of the monologue, but the results indicate that the future responses have been more fluent.

Overall, in response to the first research question of the study, it can be claimed that future responses contributed to the fluency of the monologue, albeit fitfully. The same applies to the second research question, that is, two out of the three measures of hesitation fluency witnessed better fluency results in the future tense responses. Finally, as for the third research question, it can generally be stated that future responses have been more fluent in this study. 


\section{CONCLUSION}

The aim of the present study was to investigate the possible effects that changing the verb tense of a monologue can have on the fluency of the talk. To do so, the participants of the study replied to three questions, one about a past experience, the other about a present habit, and the third about a future speculation.

The results revealed that the best fluency measures were overall observed in future responses. Mehnert (1998) manipulated the length of planning time and found that more planning time contributed to fluency in his participants. The present study, however, did not change the planning time as the planning time was the same for the three questions. Still, it is speculated that the participants might have had better ideas to talk about in case of the future tense question because the participants were all TOEFL iBT candidates, who were going to emigrate to other countries to further their education, and they must have had clear plans for the following years. As the participants asserted, one of the factors that contributed to the number and length of pauses in their responses was weather each given response was the truth or just a lie in response to any given question. Because the participants in some cases did not have any true experience about some questions and they were supposed to plan on their responses in just 15 seconds, they were sometimes forced to make up some responses that had not actually happened to them in reality, which could negatively affect the fluency of the talk. In fact, the analogy is that the planning time serves as a preparatory stage for the speakers to plan both on the content and the form of their responses. Therefore, due to the fact that they mostly had clear plans for their near future, they could use their planning time in favor of the form they wanted to use; hence better fluency results for the future tense responses. This is confirmed by other studies (e.g., Foster \& Skehan, 1996) that associate positive effects of pretask planning on fluency. In addition, Gilabert (2007) worked on planned and unplanned talks and analyzed the measures of CAF under these two conditions. The results of that study also indicated that planned responses were more fluent than unplanned ones. Therefore, it can be argued that having a clear plan of what is going to be said contributes to the fluency of that talk. By the same token, Mehnert (1998) indicated that planning had a significant effect on fluency, especially in speech rate, which is similar to the results presented in this study.

On the other hand, Yuan and Ellis (2003) found no significant difference between the fluency of pretask planners and no planners in their study. The results they obtained are contrary to the results of their previous studies (e.g., Foster \& Skehan, 1996; Mehnert, 1998; Wendel, 1997) that have all reported more fluent responses for pretask planners. Yuan and Ellis (2003) explain that, contrary to the previous studies (e.g., Mehnert, 1998; Ortega, 1999; Wendel, 1997), their participants were required to perform the tasks of the study under time pressure, and this might have caused the change in the results they obtained. The present study also required the participants to respond to the questions under time pressure, but there were differences in the fluency observed across the three responses. As the planning time and response times were both equal in the three responses, it could be argued that the observed differences might be attributed to the fact that in case of the future tense question, for instance, the participants have had better plans of how to respond and what to say, hence better fluency gains in such responses.

\section{APPENDIX The QUestions UsED IN THIS STUDY}

1. Describe the happiest day of your life. Provide reasons and examples to support your response.

2. How do you spend your free time? Provide reasons and examples to support your response.

3. How do you think your life will change in the next five years? Provide reasons and examples to support your response.

\section{REFERENCES}

[1] Bygate, M. (2000). Effects of task repetition on the structure and control of oral language. In M. Bygate, P. Skehan, \& M. Swain (Eds.), Researching pedagogic tasks: Second language learning, teaching and testing (pp. 23-48). Harlow, UK: Longman.

[2] Cucchiarini, C., Strik, H., \& Boves, L. (2002). Quantitative assessment of second language learners' fluency: Comparisons between read and spontaneous speech, The Journal of the Acoustical Society of America, 111(6), 2862-73.

[3] DeKeyser, R. (2007). Practicing in a second language: Perspectives from applied linguistics and cognitive psychology. New York: Cambridge University Press.

[4] Derwing, T., Rossiter, M., Munro, M., \& Thomson, R. (2004). Second language fluency: Judgments on different tasks. Language Learning, 54(4), 655-679.

[5] Dewaele, J. M. (2002). Individual differences in L2 fluency: The effect of neurobiological correlates. In V. Cook (Ed.), Portraits of the L2 user (pp. 219-250). Clevedon, England: Multilingual Matters.

[6] Ejzenberg, R. (2000). The juggling act of oral fluency: A psycho-sociolinguistic metaphor. In H. Riggenbach (Ed.), Perspectives on fluency (pp. 287-313). Ann Arbor: University of Michigan Press.

[7] Ellis, R. (2003). Task-based language learning and teaching. Oxford University Press.

[8] Fillmore, C. J. (1979). On fluency. In D. Kempler, \& W. S. Y. Wang (Eds.), Individual differences in language ability and language behavior (pp. 85-102). NY: Academic Press.

[9] Foster, P., \& Skehan, P. (1996). The influence of planning and task type on second language performance. Studies in Second Language Acquisition, 18(3), 299-323.

[10] Freed, B. (1995). Second language acquisition in a study abroad context. Amsterdam: John Benjamins. 
[11] Freed, B. F. (2000). Is fluency, like beauty, in the eyes (and ears) of the beholder? In H. Riggenbach (Ed.), Perspectives on fluency (pp. 243-265). Michigan: The University of Michigan Press.

[12] Guillot, M. N. (1999). Fluency and its teaching. Clevedon, U.K: Multilingual Matters.

[13] Hilton, H. (2008). The link between vocabulary knowledge and spoken L2 Fluency. Language Learning Journal, 36(2), $153-66$.

[14] Inoue, C. (2010). Investigating the sensitivity of the measures of fluency, accuracy, complexity and idea units with a narrative task. Paper presented at the Conference on Linguistics and Language Teaching. Lancashire, England: Lancaster University.

[15] Koponen, M., \& Riggenbach, H. (2000). Overview: Varying perspectives on fluency. In H. Riggenbach (Ed.), Perspectives on fluency. The University of Michigan Press.

[16] Kormos, J. (1999). The effect of speaker variables on the self-correction behavior of L2 learners. System, 27, $207-221$.

[17] Kormos, J., \& Dénes, M. (2004). Exploring measures and perceptions of fluency in the speech of second language learners. System, 32(2), 145-64

[18] Lennon, P. (1990). Investigating fluency in EFL: A quantitative approach. Language Learning, 40, 387-417.

[19] Mehnert, U. (1998). The effects of different lengths of time for planning on second language performance. Studies in Second Language Acquisition, 20, 52-83.

[20] Möhle, D. (1984). A comparison of the second language speech production of different native speakers. In H. W. Dechert, D. Möhle, \& M. Raupach (Eds.), Second language productions (pp. 26-49). Tubingen: Gunter NarrVerlag.

[21] Ortega, L. (1999). Planning and focus on form in L2 oral performance. Studies in Second Language Acquisition, 20, $109-148$.

[22] Riggenbach, H. (1991). Toward an understanding of fluency: A microanalysis of nonnative speaker conversations. Discourse Processes, 14, 423-441.

[23] Skehan, P. (1992). Strategies in second language acquisition. Thames Valley University Working Papers in English Language Teaching, 1, 178-208.

[24] Skehan, P. (1996). A framework for the implementation of task-based instruction. Applied Linguistics, 17(1), 38-62.

[25] Skehan, P., \& Foster, P. (1999).The influence of task structure and processing conditions on narrative retellings. Language Learning, 49, 93-120.

[26] Tavakoli, P., \& Skehan, P. (2005). Strategic planning, task structure, and performance testing. In R. Ellis (Ed.), Planning and task performance in a second language (pp. 239-77). Amsterdam: Benjamins.

[27] Towell, R., Hawkins, R., \& Bazergui, N. (1996). The development of fluency in advanced learners of French. Applied Linguistics, 17(1), 84-119.

[28] Wood, D. (2001). In search of fluency: What is it and how can we teach it? Canadian Modern Language Review, 57(4), 573589.

[29] Yuan, F., \& Ellis, R. (2003). The effects of pretask planning and online planning on fluency, complexity and accuracy in L2 oral production. Applied Linguistics24, 1-27.

Ali Akbar Jafarpour is an assistant professor at Shahrekord University. His area of research includes ESP, ELT, and SLA research. He has published articles in both national and international journals as well as a book on academic writing. Also, he has given lectures in national and international conferences.

Mahmood Hashemian is an assistant professor at Shahrekord University. His area of research includes cognitive-semantic linguistics, sociolinguistics, and applied linguistics. He has published articles in academic journals such as IJAL, IJLS, JALS, Linguistik-Online, JLTR, TPLS, Iranian EFL Journal, and International Journal of Social Sciences. Also, he has given lectures in several national and international conferences such as TELLSI (4, 7, 8, \& 9), LDP2010 (Ahvaz, Iran), ELT in the Islamic World (Tehran, Iran), $2^{\text {nd }}$ International Language Conference 2011 (Malaysia), the $1^{\text {st }}$ Thammasat ELT International Conference: Voices in ELT (Thailand), and $1^{\text {st }}$ Akdeniz Language Studies Conference 2012 (Turkey).

Majid Raftai is now an M.A. TEFL student at Shahrekord University. His areas of interest include sociolinguistics and cognitive linguistics. And, he has been teaching English at various language institutes for more than five years. 